\title{
Una tendencia imparable
}

\author{
Keywords: Derecho Animal; Bienestar Animal; ballenas; focas
}

El año que dejamos atrás, 2014, confirma lo que se podría calificar como una "tendencia imparable", que es la decidida sensibilización en contra del maltrato animal en el mundo y, como no podría ser de otro modo, también en España.

La labor que están haciendo muchos ciudadanos desde la sociedad, las organizaciones humanitarias, la política y, ahora, desde la Universidad (sobre todo, la UAB (www.derechoanimal.info), se ha traducido en una serie de resultados y esfuerzos que nos alientan a seguir adelante y a esperar del 2015, que, lo que hoy empieza a ser tendencia, se consolide como un logro que desarraigue el maltrato animal sistemático y avancemos globalmente en la empatía y la compasión hacia los animales. Es uno de los retos que el Derecho tiene ante sí.

Una somera revisión de lo que ha acontecido en 2014, permite un optimismo fundado.

En mayo de 2014, la OMC (=Organización Mundial del Comercio) dió un paso adelante, al ratificar el derecho de la UE a prohibir el comercio de productos derivados de la cacería de focas, lo que supone un importante mensaje a países como Canadá y USA, aún renuentes a fijar límites claros en sus legislaciones contra la crueldad animal [1]

La prohibición de experimentar con animales en la industria cosmética, que ha sido objeto de una pormenorizada legislación de la UE -por fín aceptada también por España[2] -, se ha extendido a países como India e Israel, lo que supone la prohibición de experimentar con animales en productos cosméticos y así mismo, la prohibición de la venta de productos cosméticos testados con animales. Estas medidas representan el cierre de un mercado potencial para dichos productos de 1,7 millones de personas. China también ha empezado a revisar una legislación claramente obsoleta en tema de experimentación animal, que deseamos que culmine a lo largo del 2015.

En marzo, La Corte Internacional de Justicia, se pronunció en contra de la caza de ballenas por parte de Japón, con el argumento de que dicha práctica viola la Convención Internacional sobre la regulación de la cacería comercial de ballenas. La noticia tuvo un gran impacto mediático y en septiembre la reunión de la Comisión Ballenera Internacional celebrada en Slovenia, votó de forma mayoritaria a favor de una resolución que revise los estándares sobre la necesidad de la cacería de ballenas y los eleve, de forma que se restrinja lo que en la actualidad, no pasa de ser una norma ambigua.

Uno de los grandes logros a nivel mundial, con gran repercusión en la industria alimentaria, ha sido la adopción de la prohibición de las jaulas de gestación, en las que la UE ha sido pionera y se aplicó en España en enero del 2013[3]. En efecto, Canadá, India y Brasil se han comprometido a revisar la regulación relativa a las cerdas gestantes y a equiparar sus estándares a los establecidos de forma firme por la UE.

También se cierra el año con dos grandes noticias, como la de la prohibición de circos con animales en

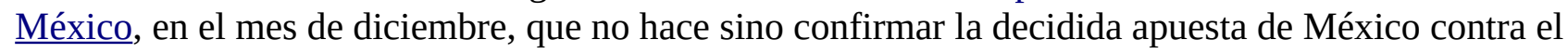
maltrato animal, de la que adelantamos en su momento una noticia, confirmada felizmente pocos meses mas tarde[4]. 
La otra gran noticia ha sido la aprobación del Habeas Corpus a la orangután Sandra, cuya defensa ha sido realizada por la Asociación AFADA. Queda por ver el alcance de tal concesión y si, efectivamente el reconocimiento de Sandra como "ser vivo con capacidades cognitivas", resulta un punto de arranque para el reconocimiento judicial de los intereses de los animales y de su respecto efectivo, a través de una legislación coherente con los mismos.

En este sentido, l'Assamblée Française, realizó una declaración relativa al reconocimiento de los animales como seres vivos dotados de sensibilidad ("êtres vivants doués de sensibilité" ) de indudable importancia. Sin embargo, queda un sabor agridulce tras esta declaración, que tras los trabajos realizados por iniciativa del Senado francés en el último trimestre del 2013[5], hubiera debido ser más ambiciosa y con una perspectiva más adaptada a los cambios en la Constitución de la República y del Code civil, que se demandan por parte de la comunidad francesa, tanto intelectual como social[6].

Por último y en lo referente a España, ha quedado pendiente de aprobación una legislación gubernamental reguladora de la tenencia y comercio de animales de compañía. Bien es cierto, que ha habido muchas consultas para avanzar en esta deseada y necesaria legislación de la que no se sabe nada de momento, pero en lo que toca a la sensibilidad social, España en estos meses que quedan atrás, ha dado pasos importantes hacia un cambio. No sólo fue demostrativa de una mayor empatía y respeto por los animales el caso de "Excalibur", sino también la aplicación sin problemas de la nueva normativa que acepta a los animales en el Metro de Barcelona, promovida por el Ajuntament de Barcelona con la colaboración del SGR Grupo de Investigación ADS de la UAB () y que empieza a tener repercusión en otras ciudades como Madrid, lo que esperamos que se regule sin dilación. En el mismo sentido, las protestas sociales contra espectáculos cruentos con animales, aparte de las corridas de toros, han sido la tónica generalizada de los meses de verano[7].

Se trata sólo de un somero muestreo de lo que los animales empiezan a significar para la sociedad, el despertar de una conciencia de empatía que no tolera el maltrato de estos compañeros de vida. Por ello, en este nuevo año, entramos con el deseo de que esas reformas se consoliden y sigamos avanzando en favor del respeto y la protección animal.

LA EDITORA

Teresa Giménez-Candela

Catedrática de Derecho Romano

Directora del Master en Derecho Animal y Sociedad Directora del SGR Grupo de Investigación ADS

Universitat Autònoma de Barcelona

Sígueme en Facebook: https://www.facebook.com/editora.da

[1] Vid. la primicia publicada por S.BRELS, Chasse aux foques à l'OMC: Bien-être animal et moralité publique en débat; Scoop de 2013: l'OMC devient pro-bien-être-animal; La OMC avala la prohibición de la UE sobre la comercialización de los productos de foca

[2] Sobre esta cuestión, hemos publicado en la web artículos, comentarios de sentencia y documentos, así como dirigido trabajos de investigación (TFM) en el Master en Derecho Animal y Sociedad, que aquí sólo menciono a título de ejemplo, pero que el lector interesado puede localizar en su totalidad en el buscador de la web, mediante la inserción del término "experimentación". Cfr. P.VERGARA, Nueva legislación sobre los animales utilizados en experimentación; K.HESSLER, Philosophical Foundations and Animals in Testing: Concerns and Consequences; M. Giménez-Candela, Cosmética y Experimentación en Animales; A.Mulà, Experimentación con animales: Sentencia del Tribunal Superior de Justicia de Cataluña n 315 de 31.1.2006; Conferencia: Il Diritto dei Cosmetici. Regolazione, responsabilità, Bioetica; M. BERGĖRE, Comentario sobre el libro de Georges Chapouthier y Françoise Tritani-Potteaux, Le Chercheur et la Souris (Paris 2013); M. González Lacabex, La ciencia también de su lado; M. Pumarola, Animals e Investigació en Neuropatología Veterinaria; F. RESCIGNO, El Derecho de los Cosméticos. Responsabilidad, Bioética; E. MIRAS LARA, Analisis legislativo estatal sobre protección de los animales utilizados en experimentación y otros fines científicos.

[3] GIMÉNEZ-CANDELA, T., Más espacio es las granjas de cerdos

[4] Vid. E.MONTERO ROMERO, Comentario respecto a la prohibición de circos con animales en México: debate social y propuestas legales

[5] Vid. M. GIMÉNEZ-CANDELA, A cara descubierta en favor de los animales, Francia, el Code civil y la Constitución

[6] T.AUFFRET VAN DER KEMP, Statut juridique de l'animal: quoi de neuf, en Droit Animal, Éthique et Sciences, Octobre 2014, ${ }^{\circ}{ }^{8} 83$, p.9s.

[7] Vid. M. GIMÉNEZ-CANDELA, La gran burrada 
